\title{
INVESTIGATING THE EFFECT OF ORDER RELEASE POLICIES IN SCHEDULING A DYNAMIC JOB PRODUCTION SYSTEM SIMULATION MODELING AND ANALYSIS
}

Vinoj $\mathrm{K}^{1}$

Abstract- This paper presents the salient aspects of a simulation study carried out to investigate the effect of order release methods on the performance of a job shop production system. Two methods of order release such as immediate release and flow allowance based release are considered. A discrete-event simulation is developed for the purpose of experimentation. A number of scheduling rules are incorporated in the simulation model for the scheduling of jobs on machines. The analysis of simulation results reveal that for the system considered, immediate release policy provides better performance.

Keywords: Dynamic Job Shop Scheduling, Order Release, Simulation.

\section{INTRODUCTION}

The job shop scheduling problem may be characterized as one in which a number of jobs, each comprising one or more operations to be performed in a specified sequence on specified machines and requiring a certain amount of time, are to be processed. The objective usually is to find a processing order on each machine such that a chosen measure of performance is optimized. In a dynamic job shop, jobs arrive at the shop continuously over time, so that the shop behaves like a network of queues. The most common approach to scheduling dynamic jobs is to use scheduling rules $[1,2,3]$. A job shop could be classified into an open shop and a closed shop, depending upon the way in which jobs are routed in the shop. In a closed shop, the number of routings available to a job is fixed and an arriving job can follow one of the available routings. In an open shop, there is no limitation on the routing of a job and each job could have a different routing. An open job shop is considered in the present study.

It is known in practice that controlling input rate has a great impact on the system performance. In manufacturing systems, this input regulation is performed by the Order Review/Release (ORR) function which is also referred to as input sequencing, input/output control and controlled release $[4,5]$. As an order arrives to the shop, it is immediately placed in pre-shop buffer. The ORR policy controls the release of the orders into the shop. Upon entering the shop, the order becomes work in process inventory as the material necessary for its production would be released.

The timing of release decisions is important because early releases cause congestion in the shop floor, possibility of damage and obsolescence, higher inventory holding costs, occupation of valuable factory space, and interference with urgent jobs. On the other hand, late releases can result in missed due-dates, loss of goodwill, idle resources, and increased lead times. Hence, ORR systems should be designed carefully and implemented effectively. Bergamaschi et al. [4] present a review of the techniques of ORR that are used in workload control systems to determine which jobs have to be selectively dispatched to the shop floor and when job release is to take place.

The present study deals with developing a simulation model for a dynamic job shop and conducting studies using the following order release policies: (1) Immediate order release and (2) Flow allowance based order release. Different scheduling rules are considered for the scheduling decision. The rest of the paper is organized as follows. Section 2 describes the job shop configuration and job data. Section 3 describes the order release method, scheduling rules and the performance measures used in the present study. The salient features of the simulation model developed are presented in section 4 . The details of experimentation, results and discussion are provided in section 5. Conclusions are presented in section 6 .

\section{JOB SHOP SYSTEM CONFIGURATION}

A realistic job shop system configuration has been developed for investigation in the present study. This configuration has been determined based on the configuration of job shops considered by various researchers. Most of the studies have used between four and ten machines. Hence, in the present study, a job shop system consisting of six machines is chosen. The machines are not identical and perform different operations. The following are the assumptions made.

1. There is only one machine of each type in the shop.

2. Each machine can perform only one operation at a time on any job.

\footnotetext{
${ }^{1}$ Associate Professor, Department of Mechanical Engineering, Viswajyothi College of Engineering \& Technology, Vazhakulam, Muvattupuzha, Ernakulam, Kerala
} 
3. An operation of a job can be performed by only one machine at a time.

4. Once an operation has begun on a machine, it must not be interrupted.

5. An operation of a job cannot be performed until its preceding operations are completed.

6. There are no alternate routings, i.e. an operation of a job can be performed by only one type of machine.

7. The setup times of jobs on machines are sequence independent and are included in the processing times.

8. Each machine is continuously available for production, i.e. no machine breakdowns.

9. There is no restriction on queue length at any machine

\subsection{Job Data}

Each job consists of a set of operations to be performed on the machines in the shop. The number of operations for each job is uniformly distributed in the range 3-6. The routing of a job through the machines is determined by random assignment. The routing is established in such a manner that a machine is included in the routing not more than once. Processing times for operations are generated from an exponential distribution with a mean of 30 minutes. It has been observed in the literature that in job shops, the distribution of the job arrival process closely follows the Poisson distribution. Hence, the time between arrivals of jobs is exponentially distributed. The mean of this exponential distribution is determined for a specified shop utilization percentage and the processing requirements of the jobs. Thus, the mean inter arrival time of jobs is obtained using the following relationship:

\section{$\mathrm{a}=\frac{\mu / \mathrm{g}}{U m}$}

$\mathrm{a}=$ Mean inter arrival time, $\mu_{\mathrm{p}}=$ mean processing time per operation, $\mu_{\mathrm{g}}=$ mean number of operations per job, $\mathrm{U}=\mathrm{Shop}$ utilization, $\mathrm{m}=$ number of machines in the shop

In the present study, $\mu \mathrm{p}=30, \mu \mathrm{g}=4.5, \mathrm{~m}=6, \mathrm{U}=.85$

The total work content (TWK) method has been used for due date assignment. The due date of a job is determined using the following equation.

$\mathrm{d}_{\mathrm{i}}=\mathrm{a}_{\mathrm{i}}+\mathrm{kp}_{\mathrm{i}}$

where $d_{i}=$ Due date of job $i, a_{i}=$ Arrival time of job i, $k=$ Due date tightness factor, $p_{i}=$ Total processing time of job $i$. In the present simulation study, $\mathrm{k}$ is fixed 5.

\section{ORDER RELEASE METHODS, SCHEDULING RULES AND PERFORMANCE MEASURES}

\subsection{Order release Methods}

The order release methods chosen for investifation in the present study are as follows.

(1) Immediate Release (IMR)

This mechanism releases jobs to the shop immediately. Here release time of a job is equal to arrival time of that job.

(2) Flow Allowance Based Release Method (FABM)

$\mathrm{R}_{\mathrm{i}}=\mathrm{d}_{\mathrm{i}}-\mathrm{F}$

where,

$R_{i}=$ Release time of job i; F = Flow allowance; $\quad d_{i}=$ Due date of job i

In the present study, three different values for $\mathrm{F}$ are used. i.e., $\mathrm{F}$ is set equal to 540, 570, 600 minutes. Based on a preliminary study, these values are found to represent the flow allowances that can be assigned to the jobs.

\subsection{Scheduling Rules}

A scheduling rule is used for scheduling the jobs to be processed on a machine. When a machine becomes free, it has to be decided which of the waiting jobs (if there is any in the queue of the machine) is to be processed on the machine. For making this decision, a scheduling rule is used to assign to each of the waiting jobs, a priority value. The job having the highest priority, which is defined by the smallest priority index is selected for processing next. In the present study, nine scheduling rules from the literature are used. These are described as follows.

(1)Shortest Processing Time (SPT)

From the waiting jobs, the one that has the shortest processing time in that work centre is selected next for processing.

(2) Shortest Remaining Process Time (SRPT)

The jobs which has minimum remaining process time is selected next for processing.

(3) Earliest Modified Due Date (EMDD)

The job which has minimum value of modified due date is selected next for processing.

Modified Due Date of a job = Max. \{ original job due date, Current time + remaining processing time of job $\}$

(4) Earliest Operation Due Date (EODD)

The job with the least operational due date is chosen for processing.

Operational due date for the first operation of job $\mathrm{i}$,

$\mathrm{ODD}_{\mathrm{i} 1}=$ Arrival time of job $\mathrm{i}+\mathrm{K}$. Processing time of operation 1 of job $\mathrm{i}$ 
In general,

Operational due date for the jth operation of job $\mathrm{i}$,

$\mathrm{ODD}_{\mathrm{ij}}=\mathrm{ODD}_{\mathrm{i}, \mathrm{j}-1}+\mathrm{K}$.Processing time of operation $\mathrm{j}$ of job $\mathrm{i}$

(5) Earliest Modified Operation Due Date (EMODD)

Modified Operation Due Date of operation j of job i = Max. \{original operation due date, Current time + processing time of operation $\}$

The job with minimum value modified operation due date is selected.

(6) Slack (S)

Choose the job which has minimum value of slack.

Slack $=$ due date - current time - remaining processing time

(7) Operational slack (OP - SLACK)

Choose the job which has minimum value of OP-SLACK.

Operation slack $=$ operation due date - current time - processing time

(8) Critical ratio + Shortest processing time $(\mathrm{CR}+\mathrm{SPT})$

Critical Ratio $(\mathrm{CR})=($ due date - current time $) /$ remaining processing time

Choose the job which has minimum value of $\left\{C R * p_{i j}, p_{i j}\right\}$

(9) Slack/ Remaining process time + Shortest processing time (S/RPT + SPT)

Choose the job with minimum value of $\left\{\right.$ (slack/remaining processing time) $\left.* p_{\mathrm{ij}}, \quad \mathrm{p}_{\mathrm{ij}}\right\}$

\subsection{Performance Measures}

The performance measures considered are mean flow time, mean tardiness and percentage of tardy jobs. These measures are described as follows.

(1) Mean flow time $\bar{F}$ : It is the average time a job spends in the shop.

$$
\left.\mathrm{F}=\frac{1}{n} \mid \sum_{i=1}^{n} \mathrm{~F}_{1}\right\rfloor
$$

(2) Mean tardiness $\bar{T}$, : It is the average tardiness of a job.

$$
\mathrm{T}=\frac{1}{n}\left\lfloor\sum_{i=1}^{n} \mathrm{~T}_{\mathrm{i}}\right\rfloor
$$

(3) Percentage of tardy jobs (PT):

$$
\mathrm{PT}=\frac{\mathbf{n}_{\mathrm{T}}}{\mathbf{n}} \times 100
$$

where $C_{i}=$ Completion time of job $i ; A_{i}=$ Arrival time of job $i ; D_{i}=$ Due date of job $i ; n=$ Number of jobs completed during the time interval from steady state period to simulation ending time; $F_{i}=$ Flow time of job $i ; F_{i}=C_{i}-A_{i} ; T_{i}=$ Tardiness of job $\mathrm{i} ; \mathrm{T}_{\mathrm{i}}=\max \left\{0, \mathrm{~L}_{\mathrm{i}}\right\}, \mathrm{n}_{\mathrm{T}}=$ Number of tardy jobs; $\mathrm{L}_{\mathrm{i}}=$ Lateness of job $\mathrm{i} ; \mathrm{L}_{\mathrm{i}}=\mathrm{C}_{\mathrm{i}}-\mathrm{D}_{\mathrm{i}}$.

\section{DEVELOPMENT OF SIMULATION MODEL}

In the present study, a discrete event simulation model is developed for the operation of the job shop production system. The simulation model is developed using the $\mathrm{C}$ programming language and run on a $\mathrm{PC}$ with Pentium processor. Generally, a discrete event simulation model of a system is constructed by defining the events that can occur and then modeling the logic associated with each event to capture the changing status in the system. Executing the logic associated with each event in a time ordered sequence produces a simulation of the system.

In the simulation model, the initial status of the job shop is assumed to be empty and idle. The arrival time of the first job is determined by sampling the inter arrival time from an exponential distribution with a specified mean. The simulation clock is advanced to the time of occurrence of this arrival. After the arrival of a job, its attributes such as number of operations, machine required for the operations (routing), processing times and due date are determined. In the immediate release method, the job is released at the arrival time. For the system operation under the flow allowance based release method, the job is released for processing only at the release time. When a job is released, the machine required for the first operation is identified. If that machine is idle, it processes the job. Otherwise, the job waits in the queue in front of the machine. After the completion of processing of an operation of a job by a machine, the queue in front of the machine is examined. If there is no job in the machine queue, the machine is idle; else, a job is selected based on a scheduling rule from the machine queue and the machine starts processing that job. When all the operations of the job are completed, the measures such as mean flow time, mean tardiness, and percentage of tardy jobs are determined. Then, the job leaves the shop. The simulation is run for a sufficiently long period after the shop reaches steady state.

Since the job system considered is a conceptual system, verification exercises have been carried on the simulation model. 


\section{EXPERIMENTATION, RESULTS AND DISCUSSION}

The first stage in the simulation experimentation is determining the end of the initial transient period (identification of the steady state). For this purpose, Welch's procedure described in Law and Kelton [6] is used. It is a graphical procedure consisting of plotting moving averages for the output performance measures. The end of the initial transient period is the time at which the moving averages approach a level value. In the present study, it is found that the moving averages for all the performance measures approach a level value when 150 jobs are completed. Hence, the simulation output corresponding to the first 150 jobs are not considered for the evaluation of performance measures.

\subsection{Experimentation}

Using the simulation model developed, experiments are conducted as follows:

(1) Immediate Release Policy (IMR)

Scheduling rules: 9 (SPT, SRPR, EMDD, EODD, EMODD, SLACK, OP-SLACK,

$\mathrm{CR}+\mathrm{SPT}, \mathrm{S} / \mathrm{RPT}+\mathrm{SPT})$; Flow allowance factor for due date, K: 5; Number of simulation experiments: 9.

(2) Flow Allowance Based Release Method (FABM)

Scheduling rules: 9 (same as above); Flow allowance factor for due date, K: 5; Flow allowance for release time: 540, 570, 600; Number of simulation experiments: $9 \times 3=27$

The simulation experiment for each replication is run for 300 job completions. Jobs are numbered on arrival at the system and the simulation output from jobs numbering 1 to 150 is discarded. The output for the remaining 150jobs (jobs numbering 151 to 300) are used for the computation of the performance measures. Each experiment is replicated thirty times. For each performance measure, the average over the thirty replications in each experiment is found out. The results obtained and their analyses are presented in the following section.

\subsection{Results and Discussion}

The results for the immediate release policy and the flow allowance based release policy are shown in Figure 1, 2, and 3 for the measures such as mean flow time, mean tardiness and percentage of tardy jobs respectively. Also, these Figures show the variation in performance among the scheduling rules.

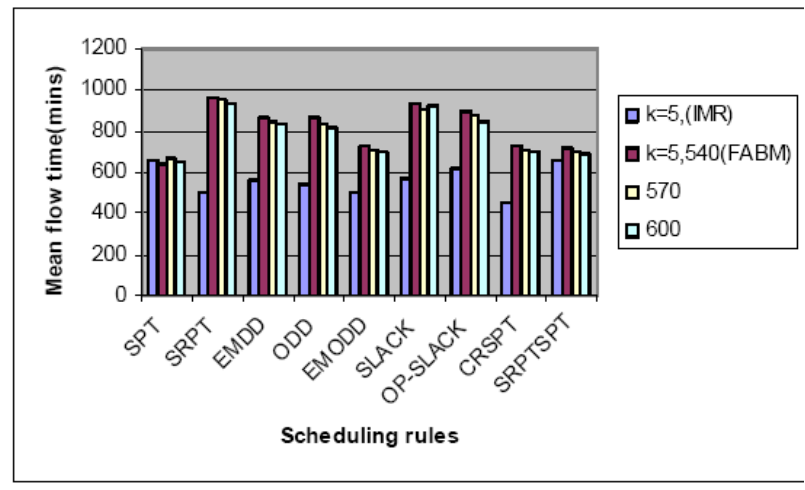

(a)

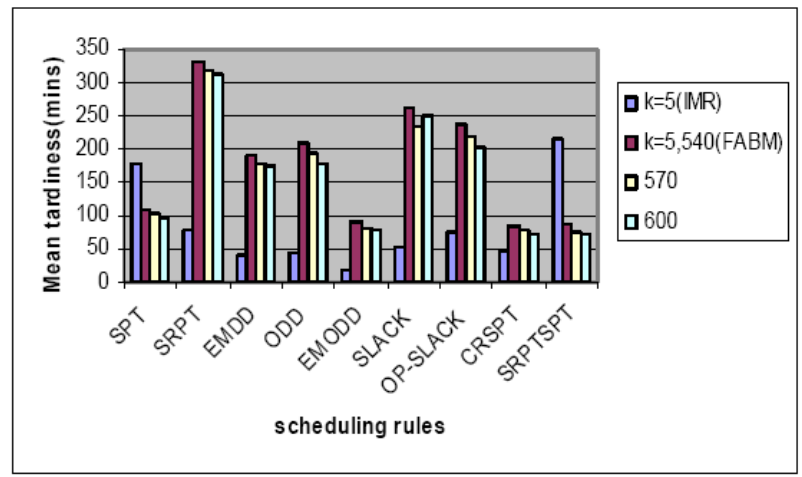

(b)

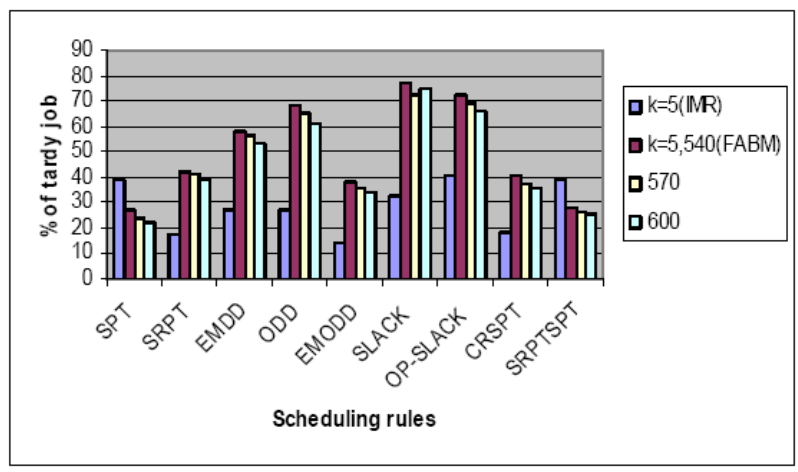

(c)

Figure 1. (a) Mean Flow Time (b) Mean Tardiness (c) Percentage of Tardy Jobs

The following are the inferences made:

(1) The immediate release policy is better than the flow allowance based release policy for all the performance measures.

(2) For the mean flow time measure, the top three best performing scheduling rules are CRSPT, SRPT and EMODD. 
(3) For the mean tardiness measure, the scheduling rules such as EMODD, EMDD, ODD and CRSPT provide smaller values. (4) For the percentage of tardy jobs measure, the scheduling rules such as EMODD, SRPT and CRSPT provide smaller values. Considering the overall performance, for the job system considered in the present study, the scheduling rules recommended are EMODD and CRSPT.

\section{CONCLUSION}

In the present work, the order release problem that arises in scheduling a dynamic job shop system is considered for investigation. A discrete event simulation model is used as a test-bed for experimentation. Two different methods of order release are implemented. Nine scheduling rules from the literature are incorporated in the simulation model. Based on the analysis of simulation results, it is found that for the system considered in the present study, immediate order release method is found to be better for all the performance measures. In the immediate order release method, EMODD and CRSPT provide better overall performance. The present work can be extended by considering other order release methods. Experiments may be conducted in a more dynamic situation involving system disruptions such as breakdowns of machines.

\section{REFERENCES}

[1] French, S, "Sequencing and Scheduling: An Introduction to the mathematics of the job-shop", Ellis Horwood Series in Mathematics and Its Applications, ed. G.M. Bell (Chichester: Ellis Hollwood Limited, 1982).

[2] Baker, K. R., "Introduction to Sequencing and scheduling", John Wiley \& Sons, Inc., 1974.

[3] Blackstone, J.H., Philips, D.T., Hogg, G.L., (1982). "A state of the art survey of dispatching rules for manufacturing job shop operations", Int. J. Prod. Res., 20, 27-45.

[4] Bergamaschi.D, Cigolini.R, Perona.M and Portioli. “A Order Review Release Strategies in A Job Shop Environment : A Review and a Classification”, International Journal of Production .RES,1997 Vol35, No2, 399-420.

[5] Sabuncuoglu.I, and Karapmar.H.Y. “ Analysis of Order Review/ Release Problems in Production Systems”, International Journal of Production Economics, 1999, Vol 62,259-279.

[6] Law. A. M, and Kelton. W.D, "Simulation Modeling and Analysis", (Third Edition), Mc Graw-Hill inc., 2000. 